\title{
A COMPLEX GENOTYPE CONTROLLING THE PRODUCTION OF MELANOTIC TUMOURS (PSEUDOTUMOURS) IN DROSOPHILA
}

\author{
C. BARIGOZZI, M. C. CASTIGLIONI and A. DI PASQUALE \\ Istituto di Genetica, Università di Milano (Italy)
}

\section{INTRODUCTION}

Received 30.iii.59

The genetical control of the production of pseudotumours in Drosophila has been studied by several authors. A survey of the data known so far can be found in Barigozzi ( I945) and Barigozzi and Di Pasquale ( $95^{6}$ ), who also produce evidence that the appearance of melanotic masses is controlled by several genes, called tu-genes (which in the stocks studied are located in the 2nd chromosome), and a complex of modifiers, probably scattered throughout the whole genotype. Castiglioni was able to demonstrate (Castiglioni and Beati, I954; Castiglioni, I956, 1957 and in press) that the following prerequisites are necessary for the production of melanotic masses during larval stages, in those stocks of $D$. melanogaster which are the object of the present investigation: (I) A structural change in the lymph gland, which can happen either through release of isolated cells or through detachment of entire lobes of the gland. (2) At least 2 per cent. of a special cell type, which differentiate as large cells, must be present in the hæmolymph, for the cells to congregate, clump and form melanin.

On the other hand large cell frequency and structural changes of the gland are independent since larvæ can have high numbers of large cells and an intact lymph gland.

Nothing can be said at present about the relation of gland disintegration and melanisation because no case is known where there is melanisation and at the same time an intact gland.

The aim of the present paper is to determine whether the different developmental conditions (frequency of large cells-gland transformation-melanisation) are genetically distinct.*

\section{MATERIAL AND METHODS}

The investigation has been carried out examining all three phenotypic traits (frequency of large cells in the larva; structure of the lymph gland in the larva; frequency of melanotic masses in the adult) in the following genotypes :

(I) Tumourless stocks : $\frac{C l B}{+} \frac{C y L}{P m} \frac{H}{S b M e^{\prime}}$, and Varese.

(2) Tumorous wild stocks: $\mathrm{A}_{2}, \mathrm{~B}_{3}$, melanotic e I44 $\dagger$ (all spontaneous).

* We are greatly indebted to Dr M. G. Pecorini, Miss G. Bertoldini and Miss C. Halfer for valuable help in preparations of the lymph glands and counting of cells.

$\dagger$ We are grateful to Prof. E. Goldschmidt for sending us the stock melanotic e 144 from Israel. 
(3) Homozygotes, where one or two chromosome pairs in the different possible combinations derive from $\frac{C l B}{+} \frac{C y L}{P} \frac{H}{S b M e^{\prime}}$ and the remainder from a tumorous stock.

(4) Isogenic chr-2 recombinants derived from crosses between tumorous stocks of the type : $\frac{C l B}{+} \frac{t u}{t u} \frac{H}{S b M e^{\prime}}$ and the marked stocks $b c n v g$ and $c n c p x$.

(5) Lines selected for high and for low production of tumours.

(6) Heterozygotes between tumorous stocks and a wild tumourless stock (Varese).

(7) Heterozygotes between different tumorous stocks.

The phenotypic data have been collected using the following techniques and methods :

(a) The frequency of melanotic masses was determined on adults. Individuals were classified into tumorous and tumourless, at a magnification of nearly 40 times.



Fig. 1.-Haemolyph cells : $a=$ small basophilic; $b=$ midsized basophilic; $c=$ large ; $d=$ crystalloid.

The number of masses per individual as well as their size was disregarded. For each genotype, several vials with single pairs were set up so as to reach a total offspring of several hundreds. Comparisons between frequencies were made using $\chi^{2} *$ first between different cultures of the same genotype then, if homogencous, between different genotypes.

(b) Frequency of large cells: counts were made on slides, on to which the largest possible amount of hæmolymph was put. The hæmolymph drop (from late 3 rd instar larvæ) was smeared and stained with May-Grünwald Giemsa mixture. Each cell was examined under the microscope (oil immersion), and classified according to four main types (small basophilic-midsized basophilic-large-crystalloid) (fig. I). No less than five larvæ have been used for each genotype.

* For testing homogeneity the Skory method was used ; for comparing two genotypes:

$$
\chi^{2}=\frac{\left(a d-b c-\frac{n}{2}\right)^{2} \times n}{(a+b)(a+c)(b+d)(c+d)} .
$$


Frequency comparisons between different genotypes or between tumourless and tumorous larvæ belonging to the same genotype, were made by analysis of variance of the frequencies after angular transformation. From Iooo to 3000 cells were counted in each late 3 rd instar larva.

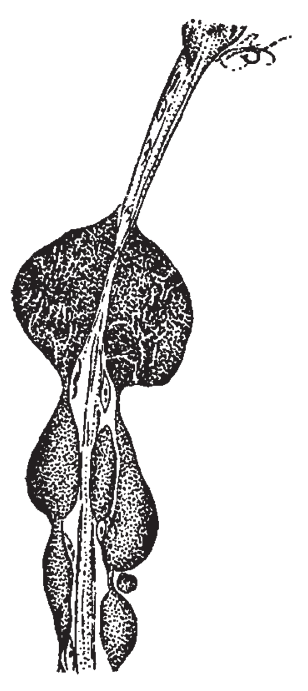

a

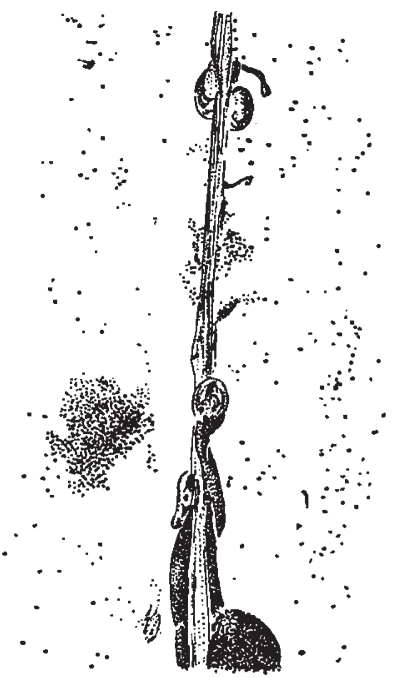

b

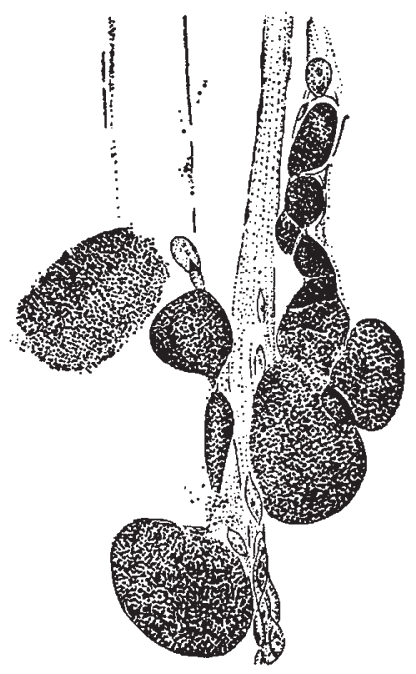

C

FIG. 2. - Lymph glands : $a=$ intact ; $b=$ dissolved through release of isolated cells; $c=$ dissolved through detachment of lobes.

(c) The aspect and the structure of the lymph gland were studied on preparations of whole glands, slightly coloured with Delafield Hæmatoxylin, and mounted in agar (fig. 2). Microtome sections have also been made, stained with hæmatoxylin-eosin. For each genotype Io-I 5 glands have been examined.

\section{RESULTS}

I. Table I shows the phenotypes of the combinations of whole chromosomes derived from the tumorous stocks, with the dominant marked chromosomes.

The table allows the following remarks: Melanisation is produced only when chromosome II is present.

Large cells. Comparing larvæ with and without tumours, in some cases ( 2 and 10 ) there is a significant difference in large cell frequency; in other cases $(4,8,9)$ such difference is not detectable. This means that the variation of frequency between individuals in the first case is high, while in the second it is low.

Frequency of large cells is controlled by chromosomes I and II. A comparison between I (tumourless stock) and 5, 6, 7, proves that the replacement of the chromosome I significantly changes the frequency 


\section{I54 G. BARIgOZZI, M. G. GASTIGLIONI AND A. DI PASQUALE}

in $B_{3}$ and perhaps $A_{2}$, but not in melanotic e 144 . Replacing the 3 rd pair (compare I with I I, I2, I3) changes are always insignificant.

The state of the gland. A difference between tumorous and tumourless larvæ appears in all genotypes involving $A_{2}$ and $B_{3}$ : a lesser one

TABLE I

Analysis of genotypes in different stocks and homozygous combinations

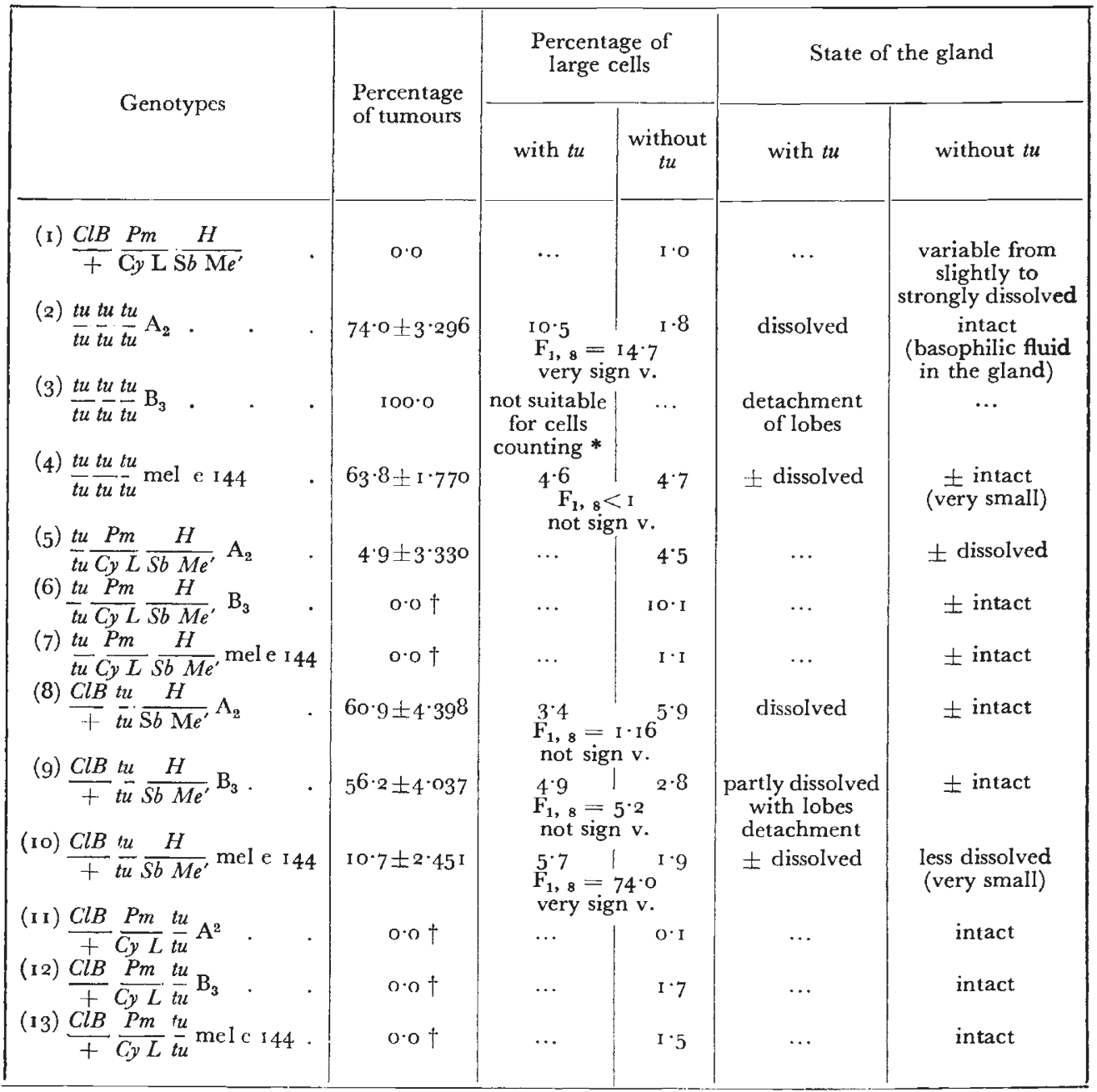

* Cells remain for the most part within the gland.

$\dagger$ All zeros reported have actually been found in countings : nonetheless other data of the same genotypes may also give very low percentages.

results in those involving melanotic e $\mathrm{I} 44$. This proves that the tumour frequency in melanotic e 144 is also due to a variable action of the melanisation genes. In fact, both the other elements are very little variable in the stock (see p. I57). 
The state of the gland is thus controlled by all three major chromosomes. A comparison between I and 5, 6, 7 proves that a slight change occurs when the ist pair is replaced. Similarly, when a replacement concerns the 2nd, a change occurs (compare I with 8, 9, I0). An

TABLE 2

Phenotype of tumourless recombinants

\begin{tabular}{|c|c|c|c|}
\hline Genotype & $\begin{array}{c}\text { Percentage of } \\
\text { tumours }\end{array}$ & $\begin{array}{c}\text { Percentage of } \\
\text { large cells }\end{array}$ & State of the gland \\
\hline$\frac{C l B}{+} \frac{\text { recomb. } \mathrm{A}_{2}}{\text { recomb. } \mathrm{A}_{2}} \frac{H}{S b M e^{\prime}} \cdot$ & $0 \cdot 0$ & $\mathrm{II} \cdot 0$ & \pm intact \\
$\frac{C l B}{+} \frac{\mathrm{recomb} . \mathrm{B}_{3}}{\text { recomb. } \mathrm{B}_{3}}$ & $\frac{H}{S b M e^{\prime}}$ \\
\hline
\end{tabular}

effect is also produced by the 3 rd chromosome (compare I with II, I 2, 13 ).

2. Chromosome II has been submitted to a more detailed analysis. Chromosomes derived from females heterozygous for chromosome II

TABLE 3

Tumour manifestation in crosses between recombinants having the same phenotype $\mathrm{cn} \mathrm{c} \mathrm{px}$ tu

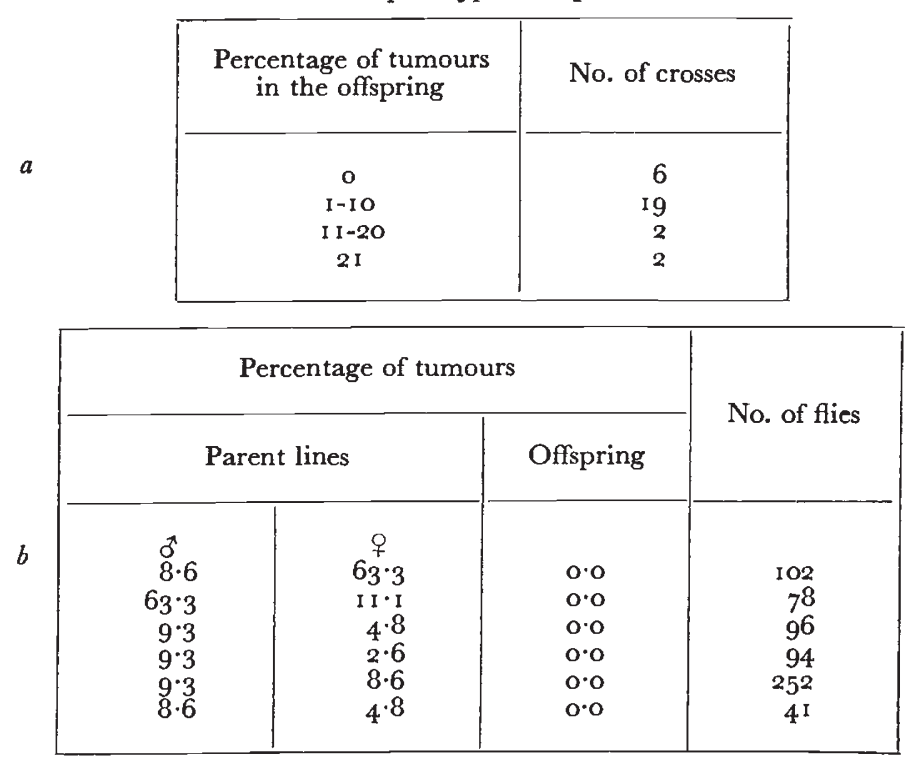

of $\mathrm{A}_{2}$ or $\mathrm{B}_{3}$ and $b c n v g$ were made isogenic. Chromosomes I and III being $C l B \mid+$ and $H \mid S b M e^{\prime}$. The $b c n$ vg stock used has a tumour manifestation of about 3 per cent., a percentage of large cells of $2 \cdot I$ and a more or less intact gland. Some of the isogenic and chromosome 
stocks so obtained were tumour free and were submitted to the usual examination for large cells and lymph gland (see table 2).

In these recombinants the cell frequency is higher than the figure recorded on table I for non-recombinants $\left(\frac{C l B}{+} \frac{t u}{t u} \frac{H}{S b M e^{\prime}}\right)$ in both $A_{2}$ and $B_{3}$ but too much reliance should not be placed on this comparison as the data in tables $\mathrm{I}$ and 2 were obtained at different times.

Recombinants were also obtained between $\mathrm{B}_{3}$ and $c n c p x$. In this case no analysis of the phenotype was made, except for classifying the adults into tumorous and non-tumorous, marked and wild.

A number of isogenic stocks all showing the same phenotype $c n c p x t u$ were intercrossed, and the results from 29 crosses are given in table $3 a$.

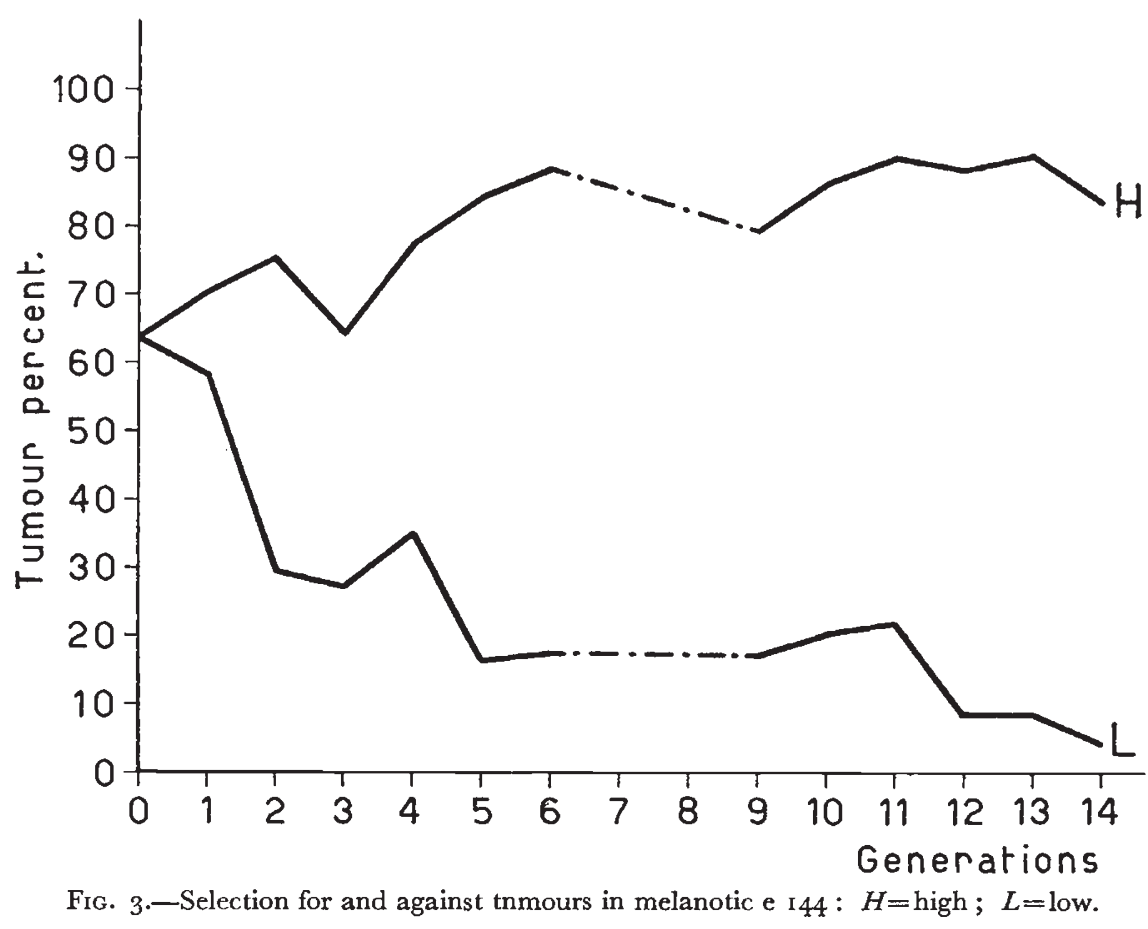

Table $3^{b}$ gives further details of the 6 crosses which have tumour-free progeny.

It appears from table 3 that the "factor" controlling melanisation can be split through recombination into a number of non-allelic parts. In other words, the melanising "gene" $t u$, is in fact a group of loci (or a complex locus), or a system of polygenes crowded in a portion of the right arm of the and chromosome (see Barigozzi and Di Pasquale, 1956).

3. Selection experiments for and against tumours have been made on melanotic e I44. Family selection was used; in each generation ten cultures were set up and the progeny showing the highest or lowest 
incidence of tumour in the respective lines was used to set up the next generation. This selection pressure of io per cent. was applied for I 2 generations.* The results are given in table 4 and fig. 3 .

TABLE 4

Selection for and against tumours in melanotic e 144

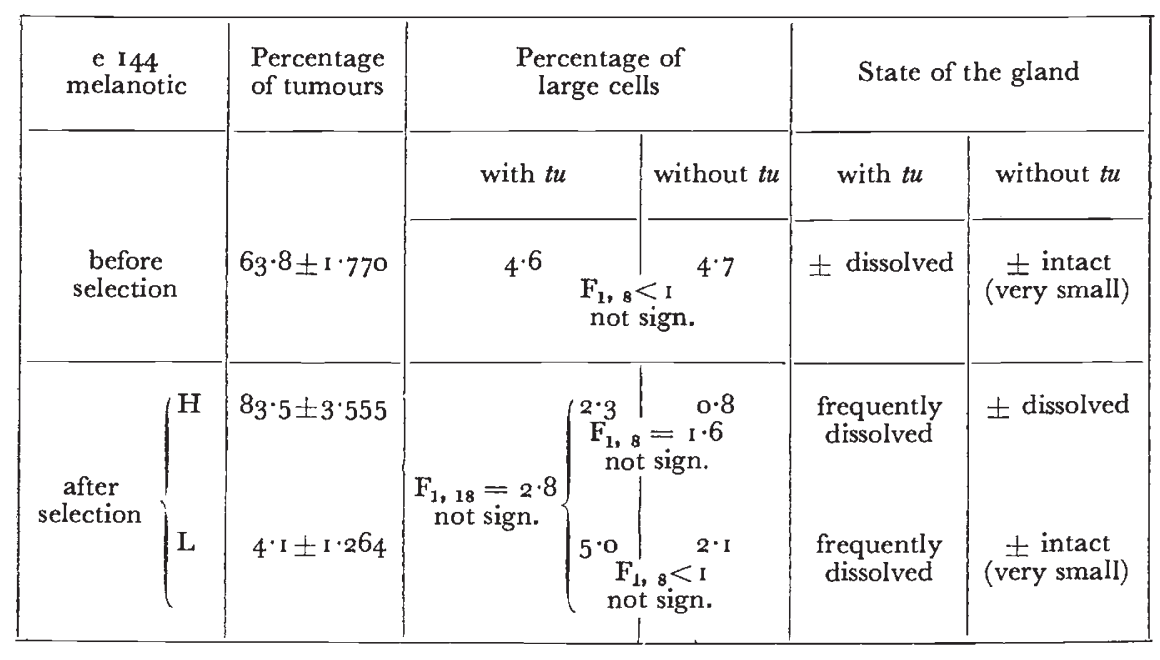

$\mathrm{H}=$ high. $\quad \mathrm{L}=$ low.

In the $\mathrm{I}_{2}$ th selected generation $\mathrm{H}$ and $\mathrm{L}$ lines were crossed in both directions, and the following results obtained (table 5 ).

TABLE 5

Crosses between selected lines $(H, L)$ of melanotic e 144

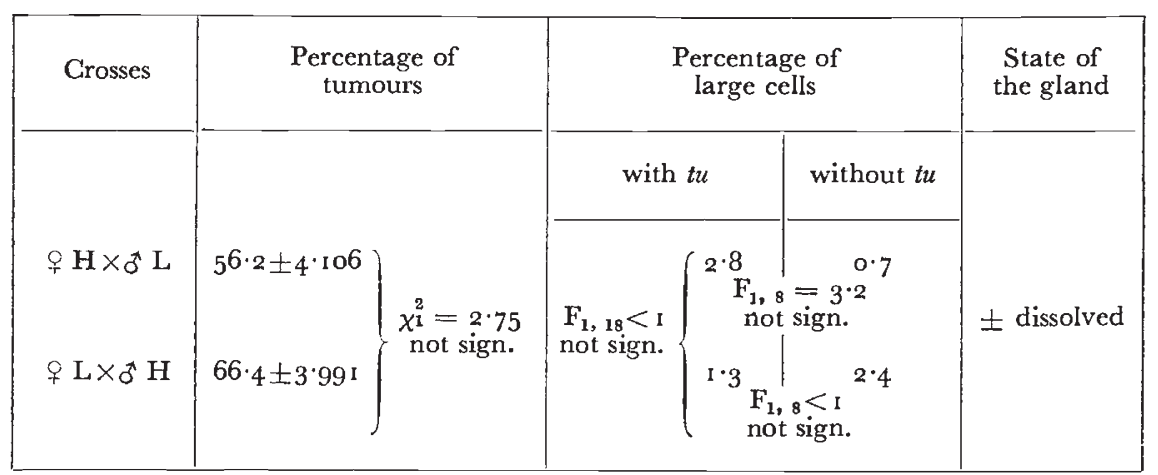

The conclusions are that: (I) selection has a clear effect on melanisation, a less clear effect on the state of the gland, and no recognisable one in the frequency of large cells. The three phenomena behave, thus, as largely independent; (2) the cross between $\mathrm{H}$ and $\mathrm{L}$ gives

* The lines were actually bred for 14 generations, but selection was not carried out in the 7 th and 8 th generations. 
practically the same result in both reciprocal crosses and in respect to tumour frequency approximate to that of the stock before selection.

4. The genetical relationship between tumorous and non-tumorous stocks has also been studied in crosses with Varese. All three characters were recorded in $F_{1}$ individuals and the results are given in table 6 . Except where indicated, no sex difference was observed.

TABLE 6

Crosses between tumorous and non-tumorous stocks (percentage of large cells and state of gland in tumourless individuals)

\begin{tabular}{|c|c|c|c|}
\hline $\begin{array}{c}\text { Genotypes } \\
\text { (cytoplasm Varese) }\end{array}$ & $\begin{array}{l}\text { Percentage of } \\
\text { tumours }\end{array}$ & $\begin{array}{l}\text { Percentage of } \\
\text { large cells }\end{array}$ & $\begin{array}{l}\text { State of } \\
\text { gland }\end{array}$ \\
\hline 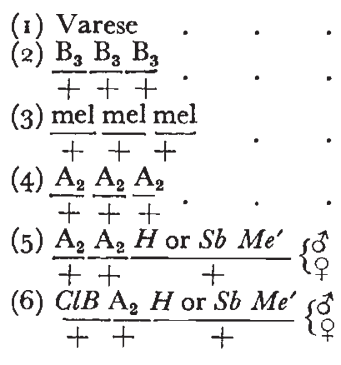 & $\begin{array}{l}0 \cdot 0 \\
1 \cdot 6 \pm 0.598 \\
0 \cdot 0 \\
2 \cdot 7 \pm 0 \cdot 799 \\
0 \cdot 7 \pm 0 \cdot 717\} x_{1}^{2}=7 \cdot 91 \\
8 \cdot 9 \pm 2 \cdot 557\}^{1} \text { sign. } \\
0 \cdot 0 \\
4 \cdot 7 \pm 1 \cdot 527\end{array}$ & 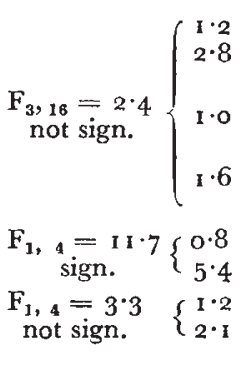 & $\begin{array}{c}\begin{array}{c}\text { intact } \\
\text { intact }\end{array} \\
\text { intact } \\
\text { intact (baso- } \\
\text { philic fluid) } \\
\text { nearly intact } \\
\pm \text { intact }\end{array}$ \\
\hline
\end{tabular}

Note: No difference has been found in reciprocal crosses except in 5 and 6.

We can conclude that: (I) all tumorous stocks behave as nearly completely recessive against Varese (tumourless) with reference to all three characters considered; (2) a peculiar trait of $\mathrm{A}_{2}$, i.e the presence of a basophilic fluid within the gland, manifests itself in the heterozygote; (3) in $\mathrm{A}_{2} /+$ heterozygotes for one single chromosome and for two chromosomes $(5,6)$ there is a significant difference between the sexes, with respect to the tumour frequency and (in 5 only) with respect to the frequency of the large cells as well. This proves an interaction between $X$ and 3 rd chromosome, because in 4 (where there is $\frac{\mathrm{A}_{2}}{+} 3 \mathrm{rd}$, instead of $\frac{+}{S b M e^{\prime} \text { or } H}$ ) the difference between sexes disappears; (4) the state of the gland, as well as the cell frequency, do not change greatly in the different crosses.

5. The genetical relationship between the tumorous stocks have also been investigated. The results are summarised in table 7 .

The conclusions are: (I) Heterozygosity produces a decrease in tumour frequency. Since this gives information about the genotypic similarity between stocks, we could arrive at this serial classification (the closer ones are the most similar): $B_{3}-A_{2}$-melanotic e 144 . All three stocks behave as giving a more or less intermediate manifestation in heterozygotes. 
(2) Heterozygosity also causes a decrease to a very low level of the frequency of large cells in $\mathrm{A}_{2} \times \mathrm{B}_{3}$ heterozygotes. No reduction (or even an increase) is produced by the presence of melanotic e 144 . The same is true of the heterozygotes for only the and chromosome.

TABLE 7

Crosses between different tumorous stocks (percentage of large cells and state of gland in tumourless individuals)

\begin{tabular}{|c|c|c|c|c|}
\hline Genotypes & & $\begin{array}{l}\text { Percentage of } \\
\text { tumours }\end{array}$ & $\begin{array}{l}\text { Percentage of } \\
\text { large cells }\end{array}$ & $\begin{array}{l}\text { State of the } \\
\text { gland }\end{array}$ \\
\hline 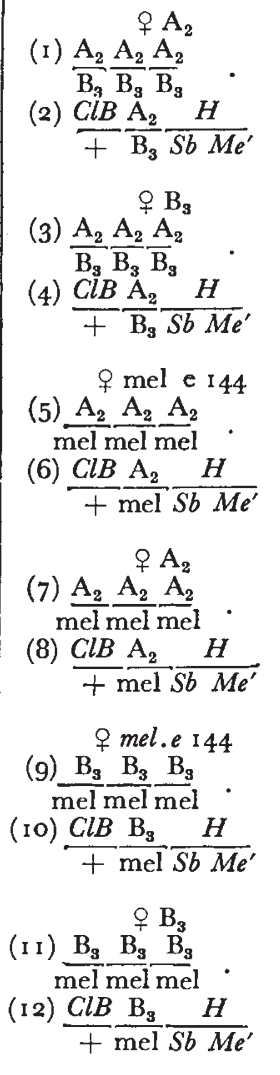 & - & 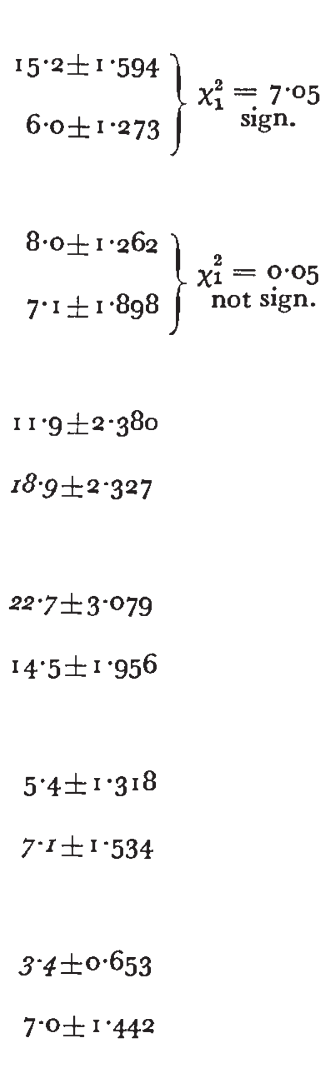 & $\begin{array}{l}\text { II } \cdot 0 \\
8 \cdot 7\end{array}$ & $\begin{array}{c}\text { variable } \\
\text { ( } \pm \text { intact) } \\
\text { variable } \\
\text { (often dissolved) } \\
\begin{array}{c}\text { variable } \\
\text { ( } \pm \text { intact) } \\
\text { variable }\end{array} \\
\text { (often dissolved) } \\
\text { intact } \\
\text { variable } \\
\text { (often dissolved) }\end{array}$ \\
\hline
\end{tabular}

Note: Italic figures refer to heterogeneous samples, thus unsuitable for further statistical elaboration.

(3) Heterozygosity between $\mathrm{A}_{2}$ and $\mathrm{B}_{3}$ induces a gland structure which resembles that of tumourless individuals of $A_{2}$; melanotic e 144 introduces a variability, which leads to an often rather high gland dissolution thus showing once more that gland dissolution is not sufficient to produce melanisation.

(4) The three elements acting on tumour production behave rather differently in the three stocks. 
(5) Where comparisons are possible $(1,2,3,4)$, the cytoplasm can exert an effcct on the tumour percentage: more precisely when $A_{2}$ cytoplasm is present, it increases the tumour frequency in $A_{2} \times B_{3}$ heterozygotes for all chromosomes, whereas heterozygotes for the 2nd pair only do not show this effect. Comparisons with heterozygotes carrying melanotic e 144 are impossible, because of the heterogeneity of the samples.

\section{GENERAL CONCLUSIONS AND DISCUSSION}

(I) In three spontaneous stocks of $D$. melanogaster, the production of pseudotumour is the result of three developmental steps (detachment of cells from the lymph gland; presence of large cells in the hæmolymph in a frequency of no less than 2 per cent.; melanisation of clumps of large cells).

(2) The first two steps are not strictly dependent in development, because it is possible to obtain tumourless genotypes with high frequency of large cells and intact gland (see table 2). Melanisation is conditioned by high frequency of large cells in the hæmolymph and a structural change in the gland as previously described. In all genotypes analysed, the process in tumorous individuals is constant, except for the mode of the displacement of the cells from the lymph gland.

(3) All chromosomes are active in controlling the production of tumours. The replacement of whole chromosomes, recombination and heterozygosity permit us, however, to distinguish distinct functions in the three main chromosome pairs: (a) melanisation, is controlled nearly exclusively by the 2nd chromosome (tu-genes), where several loci are concentrated in small portions, which can be different in different stocks. These genes behave as nearly recessive, if tested against " no melanisation", but are moderately effective in heterozygotes between tumorous stocks in spite of their different location; (b) frequency of large cells, is controlled at least by the ist and the 2nd. The 2nd pair controls this character, as well as melanisation; no elements are known concerning the 3 rd pair. These genes behave as recessive in heterozygotes; (c) state of the gland, is controlled by genes located also on all major chromosomes. Alleles producing changes in the lymph gland during larval stages behave as recessive as compared with those keeping it intact. A typical swelling is produced in heterozygotes between $A_{2}$ and $B_{3}$.

Melanisation is genetically independent of the other two phenomena in melanotic e 144 , as proved by selection experiments.

(4) The phenotype is the result of the integration of the action exerted by factors distributed unevenly (at least partially) along all major chromosomes. The melanotic tumour is, in other words, the phenotype corresponding to at least three different parts of the genome working together, each having a typical and recognisable effect. 
These findings can now be shortly discussed with respect to the main problems concerning the heredity of the quantitative characters.

A character is called quantitative when it can be described by means of measurements; this is true independently of whether it is controlled by oligogenes or by polygenes. The presence of the melanotic spots in Drosophila can be considered as a quantitative character, because, taking into consideration the incidence of the trait, the stocks can be classified into a series, going from tumour incidence of o up to Ioo per cent., including all intermediate degrees.

It should be noted that the recognition of tumours depends on the technique used (magnification, examination of sections, etc.), and stocks classified as non-tumorous at an inspection with low magnification, might reveal the presence of some very slight melanisation, when examined using more refined means of observation. Quantitative characters controlled by several genes (polygenes) are intermediate in heredity: this is not found in melanotic tumours, which behave, in the majority of the stocks studied so far, as nearly completely recessive or, rarely, as dominant. This fact seems to establish a difference between this character and other well studied examples of quantitative characters (abdominal chaetæ in Drosophila, Mather, I949). The polygenic characters have in common another property: genes are able to work together irrespective of their location, so that the final result is more or less influenced by many or by all portions of the chromosomes. This phenomenon is recognisable in melanotic tumours, because these appear with considerable incidence in crosses between tumorous stocks, although not so frequently as in the stocks. This fact favours the view that a very diffuse physiological affinity exists between distant loci, especially in stocks $A_{2}$ and $B_{3}$, where tu-genes are located at the opposite ends of the 2nd chromosome (Barigozzi and Di Pasquale, 1956).

Thus, the inheritance of the presence of melanotic masses, when compared with that of conventional polygenic characters, seems to occupy a special position, giving to $t u$-genes an intermediate position between oligogenes and polygenes.

What we have remarked about the production of melanotic masses, can be extended to both the prerequisites for their formation, i.e. the frequency of the large cells, and the behaviour of the gland. Both characters are controlled by several factors; at least three, because all three major chromosomes are involved. However, high cell frequency is recessive to low cell frequency, and dissolved gland to intact gland. Unfortunately we do not know where the factors controlling the blood cells and the lymph gland state are located along the chromosome; nothing more can be said about their behaviour in compounds.

Summarising, the production of pseudotumours forms the most complex character so far analysed in Drosophila, being brought about by at least three elementary traits, and at least three systems of factors. 


\section{SUMMARY}

I. The complicated mechanism of tumour production, already known in several tumorous stocks of $D$. melanogaster, was submitted to genetic analysis in three stocks, in order to prove whether the different developmental steps are controlled by the same or by different genes. Using different genetical techniques, evidence was found that different systems of factors are working.

2. These systems act during the larval stages. One of them controls the frequency of the hæmolymph cells; a second the behaviour of the lymph gland; a third the production of melanin by the large cells of the hæmolymph. The first and second systems are multichromosomal, while the third is localised in the and chromosome, and, in some stocks, in one restricted section of it.

3. In no case was it demonstrated that the same genes act on the different developmental steps, listed above. So the authors incline to believe that pleiotropy is not demonstrated.

4. The genes for melanisation (tu-genes), which are more suitable for investigation, have some characters in common with typical polygenes (several loci with identical or similar effect, physiological allelism between groups located in different parts of the chromosome); their recessiveness and restricted location in the genome, on the one hand, and technical reasons on the other, let them appear as controlling a discontinuous character.

\section{REFERENCES}

BARIGOzZI, c. 1954. The appearance of abnormal groups of cells during or after development: tumors and pseudotumors. Proc. IX Int. Congress of Genetics, I 953 (Bellagio) Caryologia, 6 (suppl.), 338-354.

Barigozzi, c. I 958. Melanotic Tumours in Drosophila 7. cell. comp. Physiology, 52, (suppl.), 37I-38I.

Barigozzi, c., AND DI PAsQuale, A. 1956. A contribution to the genetics of the so-called melanotic tumors (pseudotumors) of Drosophila melanogaster. Rend. Ist. Lomb. Sci. Lett., go, 484-509.

CASTIGLIONI, M. C. 1956. Nuove osservazioni sulla produzione degli pseudotumori in Drosophila melanogaster. "Atti II Riunione AGI," La Ricerca Scientifica suppl. 26, $125^{-1} 30$.

CASTIGLIONI, M. C. 1957. Le cellule dell'emolinfa di Drosophila melanogaster in relazione al genotipo e alla produzione degli pseudotumori. "Atti III Riunione AGI," La Ricerca Scientifica, suppl. 27, 5 I-58.

CASTIGLIONI, M. C., AND BEATI, G. 1954. Production of pseudotumors in Drosophila, after injection of hæmolymph. Experientia, IO, 50 I-502.

Mather, K. 1949. Biometrical Genetics. Methuen, London. 